\title{
Oxygen consumption by rat oocytes and cumulus cells during induced atresia
}

\author{
C. Magnusson*, S. Bar Ami, Ruth Braw and A. Tsafriri \\ Department of Hormone Research, Weizmann Institute of Science, Rehovot, Israel and \\ *Department of Physiology, University of Göteborg, S-400 33 Göteborg, Sweden
}

\begin{abstract}
Summary. Oxygen consumption was measured in denuded oocytes and oocyte-cumulus complexes isolated from atretic rat follicles. Adult cyclic rats or immature PMSGtreated rats were used, and follicular atresia was induced by hypophysectomy on the morning of pro-oestrus or by repeated pentobarbitone injections beginning on the day of pro-oestrus. The later stages of atresia were accompanied by meiosis-like changes in the oocytes. Oxygen consumption by oocytes that had resumed meiosis (germinal vesicle breakdown, GVB) was higher than in oocytes with an intact germinal vesicle, a change similar to that observed in oocytes maturing in healthy follicles. This may indicate that the meiotic process in the atretic follicles is similar to that in normal ones.

Oxygen consumption by the cumulus cells was not altered during pentobarbitoneinduced atresia. Hypophysectomy led to a rapid and marked increase in cumulus oxygen consumption in cyclic rats but there was no change in PMSG-treated young animals. Since both pentobarbitone-treatment and hypophysectomy result in follicular atresia, but changes in cumulus respiration occurred only in hypophysectomized adult rats, it is concluded that an increase in cumulus respiration is not inherent to the atretic process.
\end{abstract}

\section{Introduction}

Most ovarian follicles undergo atresia rather than ovulation (Byskov, 1978). The earlier stages in the process of atresia are difficult to investigate since atretic follicles can be recognized only after morphological changes have already become evident. Two approaches to study atresia in a synchronized population of follicles have been used: (1) daily injections of pentobarbitone to rats, starting on the afternoon of the day of pro-oestrus, produce atretic changes in most of the large follicles after 3-4 days (Braw \& Tsafriri, 1980; Uilenbroek, Woutersen \& van der Schoot, 1980), and (2) hypophysectomy of pro-oestrous rats leads to atresia of the preovulatory follicles by 1 day after surgery (Braw, Bar Ami \& Tsafriri, 1981).

During the later stages of the atretic process the cocyte undergoes meiosis-like changes, i.e. germinal vesicle breakdown (GVB) and extrusion of the first polar body (PB). The functional significance of these changes is still unclear. During normal oocyte maturation these events are accompanied by an increase in oocyte oxygen consumption (Magnusson, Hillensjö, Tsafriri, Hultborn \& Ahrén, 1977). The oxygen consumption by the cumulus oophorus decreases after exposure to gonadotrophin (Dekel, Hultborn, Hillensjö, Hamberger \& Kraicer, 1976) but spontaneous maturation of oocytes in culture in the absence of gonadotrophins occurs without any change in cumulus respiration (Magnusson \& Hillensjö, 1981). 
The aim of the present study was to examine (a) whether the process of atresia induced by pentobarbitone treatment or hypophysectomy results in consistent changes in oxygen consumption by the oocyte or the cumulus-oocyte complex and, if so, (b) to compare such changes with the respiration of oocytes during normal meiosis and cumulus cell respiration after gonadotrophin stimulation, respectively.

\section{Materials and Methods}

Animals. In mature and immature rats the preovulatory surge of gonadotrophins was prevented by hypophysectomy or by repeated injections of pentobarbitone sodium.

In the first series of experiments, performed in Israel, Wistar-derived rats from the departmental colony were used. The rats were housed under standardized environmental conditions (lights on 05:00-19:00 h) and showing at least two normal 4-day cycles as confirmed by daily vaginal smears, immediately before the experiment.

Hypophysectomy was performed on the morning of pro-oestrus under ether anaesthesia using the intra-aural approach (Zarrow, Yochim \& McCarthy, 1964). After killing the rats, each sella turcica was examined and only those rats having no trace of the hypophysis remaining were included in the experiments.

Pentobarbitone sodium (Nembutal, Abbott; $30 \mathrm{mg} / \mathrm{kg}$ body wt) was injected i.p. on the day of pro-oestrus between $13: 40$ and $14: 00 \mathrm{~h}$ and on the next 3 days between $13: 40-14: 00 \mathrm{~h}$ and $15: 40-$ 16:00 h. The critical period for blocking ovulation by pentobarbitone in our colony is between $13: 30$ and 16:30 h (Tsafriri \& Kraicer, 1972). All pentobarbitone-treated rats were checked for ovulation before the experiment, and discarded if tubal ova were present, or if no enlarged Graafian follicles were protruding from the ovarian surface.

In the second series of experiments, performed in Sweden, 26-day-old Sprague-Dawley rats (Anticimex, Stockholm) were injected with 10 i.u. PMSG (Sigma) and hypophysectomized $48 \mathrm{~h}$ later by the standard parapharyngeal approach under ketamine chloride anaesthesia. Completeness of hypophysectomy was confirmed by the lack of assayable GH in trunk blood collected at death (Ekholm, Hillensjö \& Isaksson, 1981). Some rats were given a second injection of PMSG (10 i.u.) immediately before hypophysectomy, a procedure previously shown to prevent the atresia that follows hypophysectomy (Braw \& Tsafriri, 1981). Pentobarbitone injections were given to PMSGtreated immature rats on the afternoon of the day of pro-oestrus, i.e. $54 \mathrm{~h}$ after administration of PMSG, and on the following days as described above for mature rats.

Isolation of cumulus complexes and oocytes. Rats were killed by cervical dislocation before the critical period on the day of pro-oestrus, on the day after the last pentobarbitone injection or at a specified time after hypophysectomy. Cumulus-oocyte complexes were isolated by incision of the largest follicles with a needle. In some experiments preovulatory follicles were isolated from prooestrous rats and cultured as previously described (Tsafriri, Lindner, Zor \& Lamprecht, 1972) before isolation of the cumulus complex. Oocytes were denuded by repeated sucking through a set of precision-made mouth-controlled micropipettes with successively smaller diameters, the smallest of which had a diameter only slightly larger than the oocyte.

Determination of oxygen consumption. Oxygen consumption of single cumulus complexes or denuded oocytes (3-4 per measurement) was determined microspectrophotometrically using haemoglobin $(45-60 \mu \mathrm{M})$ as an indicator of oxygen tension (Hultborn, 1974; Magnusson et al., 1977). Oxygen consumption by the intact cumulus complex mainly $(90 \%)$ reflects cumulus cell respiration (Ahrén et al., 1978). The cells were placed in haemoglobin-containing medium in a minute $(12.3 \mathrm{nl})$ gas-tight chamber and the increase in absorbance at $435 \mathrm{~nm}$, reflecting dissociation of oxyhaemoglobin due to lowered oxygen tension, was recorded. Each measurement required 5-15 min. In the experiments with cyclic rats Eagle's medium (Gibco) supplemented with $10 \%$ fetal calf serum (Gibco) was used, whereas in the second series of experiments with immature PMSG-treated 
rats a chemically defined medium, BMOC (Magnusson et al., 1977), was used. It has earlier been shown that the use of these two different media does not influence the measurement of oxygen consumption (Magnusson \& Hillensjö, 1981). Statistical differences were calculated by analysis of variance followed by Student-Newman-Keuls multiple range test (Woolf, 1968).

Maturation of oocytes. Immediately following the respirometry, the oocytes were examined by Nomarski interference microscopy, and the stage of meiotic maturation was determined. The oocytes were classed into three groups: immature oocytes containing an intact GV (or at least nucleolus), oocytes resuming meiosis, as shown by germinal vesicle breakdown (GVB), or oocytes completing the first meiotic division with a visible first polar body.

\section{Results}

\section{Oocyte morphology}

As shown in Text-fig. 1, the later stages of follicular atresia were accompanied by morphological changes typical of resumption of meiosis. PMSG given immediately before hypophysectomy prevented meiotic maturation for up to 2 days after hypophysectomy. Degeneration of oocytes was observed only in $5 \%$ of the atretic follicles examined up to $48 \mathrm{~h}$ after hypophysectomy or up to $96 \mathrm{~h}$ after the first pentobarbitone injection and such oocytes were excluded from the calculations. The maturation rates were in good accordance with values observed in other series of experiments, except for that at $96 \mathrm{~h}$ of pentobarbitone treatment of cyclic rats which usually leads to about $20 \%$ GVB.

- GV GVB $\quad$ G Polarbody

(a) Cyclic rats

(b) Immature rats

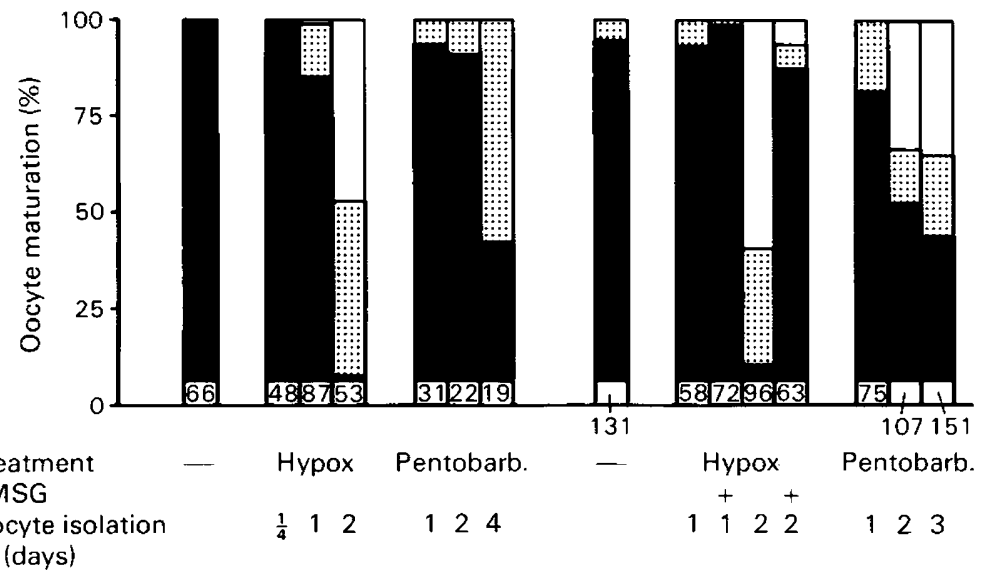

Text-fig. 1. Maturation of oocytes isolated from large atretic follicles of (a) cyclic rats hypophysectomized (Hypox) on the morning of pro-oestrus, or given daily injections of pentobarbitone (Pentobarb.) starting on the afternoon of pro-oestrus and (b) immature PMSGtreated rats hypophysectomized 2 days after PMSG injection (some rats receiving an extra PMSG injectin, + , immediately before hypophysectomy) or given daily pentobarbitone injections starting on the afternoon 2 days after PMSG injection. The number of oocytes examined is indicated at the base of the columns.

\section{Oocyte oxygen consumption}

Immature oocytes isolated from untreated cyclic pro-oestrous rats had an oxygen consumption of $0.104 \pm 0.009 \mathrm{nl} / \mathrm{h} /$ oocyte (Text-fig. 2). Oocytes explanted 6 and $24 \mathrm{~h}$ after hypophysectomy did not exhibit any significant increase in respiration. By contrast, oocytes from animals killed $48 \mathrm{~h}$ 
after hypophysectomy showed a $95 \%$ increase in respiration compared to control. While all oocytes used at $6 \mathrm{~h}$ and most oocytes used $24 \mathrm{~h}$ after hypophysectomy were immature, those examined after $48 \mathrm{~h}$ were all maturing. The maturing oocytes used $24 \mathrm{~h}$ after hypophysectomy showed a slight increase in respiration, although not significant. Pentobarbitone treatment had no effect on oocyte oxygen consumption. The small increase $96 \mathrm{~h}$ after pentobarbitone was significant $(P<0.05)$ compared with the control group but not compared with the other pentobarbitone-treated groups. In the experiments on oocyte respiration, only a few oocytes were maturing after pentobarbitone treatment, and therefore only oocytes with an intact GV were studied.

Oxygen consumption by oocytes obtained from follicles induced to undergo atresia by repeated pentobarbitone injections was more thoroughly examined in immature PMSG-treated rats. Clearly the duration of pentobarbitone treatment per se did not affect oocyte oxygen consumption. However, resumption of meiosis due to atresia resulted in a $25-50 \%$ increase in oxygen consumption regardless of the duration of the treatment (Text-fig. 2).

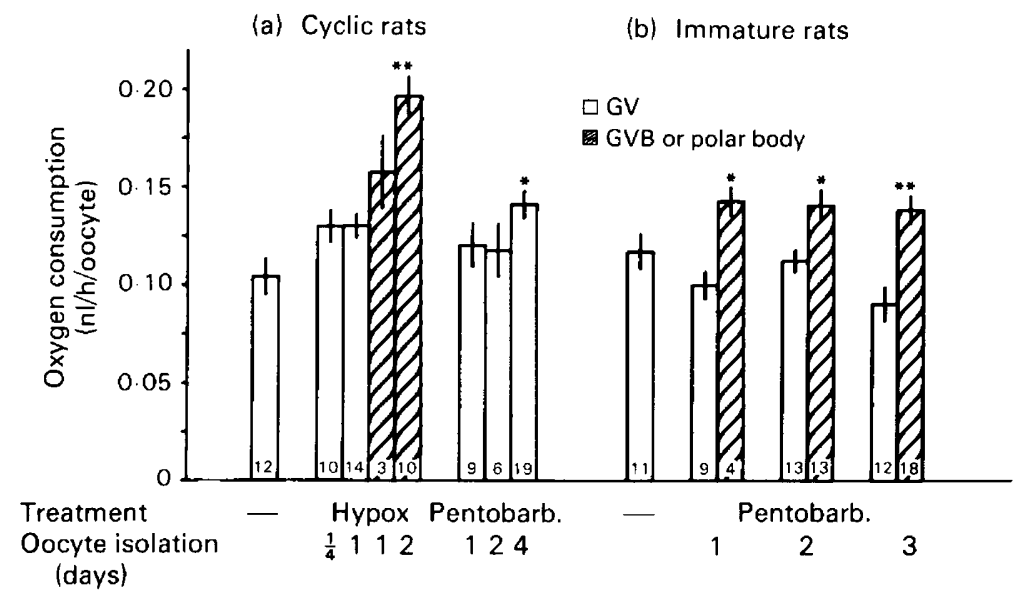

Text-fig. 2. Oxygen consumption by denuded oocytes from atretic follicles of hypophysectomized or pentobarbitone-treated cyclic or immature rats. Values are mean \pm s.e.m. for the number of measurements (3-4 oocytes in each) indicated at the base of the columns. For cyclic rats, ${ }^{*} P<0.05,{ }^{* *} P<0.01$ compared to untreated control; for immature rats, ${ }^{*} P<0.05,{ }^{* *} P$ $<0.01$ compared with value for oocytes with GV at the corresponding time (respiration of any oocytes with an intact GV did not differ from that of untreated controls).

\section{Cumulus oxygen consumption}

Cumulus complexes isolated from untreated mature pro-oestrous rats had an oxygen consumption of $1.56 \pm 0.12 \mathrm{nl} / \mathrm{h} /$ cumulus (Text-fig. 3). The respiration increased by $65-90 \%$ after hypophysectomy, the increase being maximal by $6 \mathrm{~h}$. Pentobarbitone treatment had no significant effect on cumulus respiration. Oxygen consumption by cumulus complexes isolated from follicles that had been cultured in hormone-free medium for 6 or $24 \mathrm{~h}$ was not different from control (mean \pm s.e.m. values were $1.84 \pm 0 \cdot 17(n=13)$ and $1.56 \pm 0.11(n=27) \mathrm{nl} / \mathrm{h} /$ cumulus after 6 and $24 \mathrm{~h}$ culture, respectively).

Cumuli isolated from PMSG-treated immature rats showed an oxygen consumption of $0.85 \pm$ $0.09 \mathrm{nl} / \mathrm{h} /$ cumulus $(n=12)$, which was lower than that for mature pro-oestrous rats. Nevertheless, hypophysectomy or hypophysectomy accompanied by administration of PMSG (10 i.u.) did not affect cumulus respiration (Text-fig. 3). Neither was there any difference in the respiration of cumuli containing an immature or a mature oocyte. 
(a) Cyclic rats

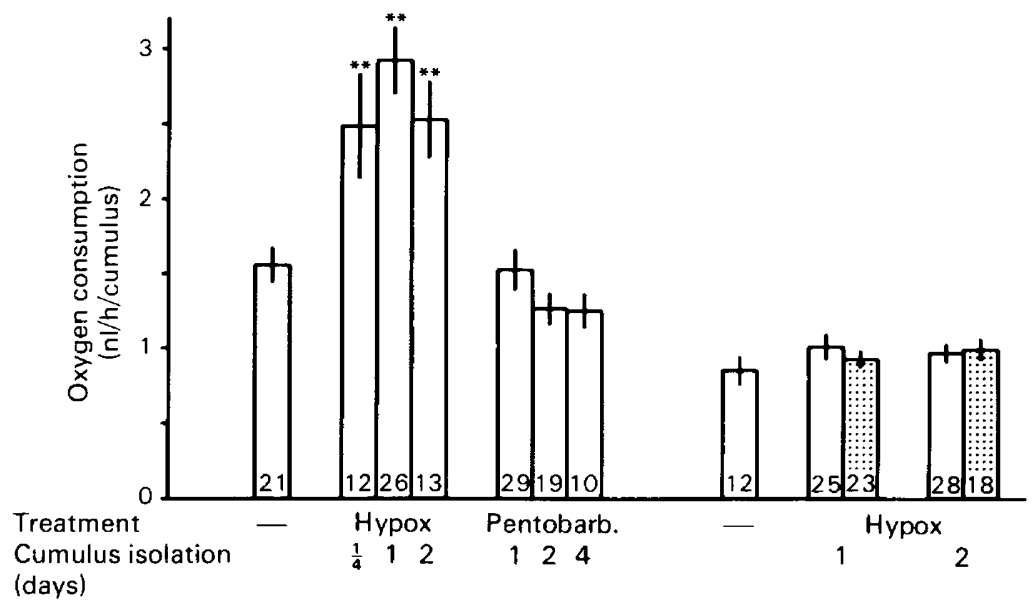

Text-fig. 3. Oxygen consumption by oocyte-cumulus complexes from atretic follicles of hypophysectomized or pentobarbitone-treated cyclic or hypophysectomized immature rats; some of the latter were given an additional PMSG injection immediately before hypophysectomy (国). Values are mean \pm s.e.m. for the number of measurements indicated at the base of the columns. ${ }^{* *} P<0.01$ compared to control value (cumuli from preovulatory follicles from untreated pro-oestrous rats).

\section{Discussion}

Follicular atresia is characterized by morphological and biochemical changes. For example, basal and $\mathrm{LH}$-induced progesterone secretion increase early during the process of atresia, whereas the secretion of androgens and oestradiol decreases (Braw \& Tsafriri, 1980; Braw et al., 1981). Another characteristic feature is that during later stages of atresia the oocyte undergoes meiosis-like changes, i.e. GVB and polar body formation. During normal maturation of the oocyte consumption of oxygen by cumulus oophorus cells and the oocyte changes characteristically (Ahrén et al., 1978). The major aim of this study was to test whether the meiosis-like changes during atresia were accompanied by similar changes in respiration.

It was found that oocyte respiration in atretic follicles followed the same pattern as during normal maturation (Magnusson et al., 1977), i.e. the resumption of the meiotic process was accompanied by an increase in respiration, whereas the respiration of the immature oocytes obtained from animals after hypophysectomy or pentobarbitone treatment did not differ from control. The increase in oxygen consumption by maturing oocytes obtained from atretic follicles of hypophysectomized animals was, however, greater than in maturing oocytes isolated from healthy follicles.

Gonadotrophins have been shown to inhibit cumulus respiration (Dekel et al., 1976; Magnusson \& Hillensjö, 1981). Nevertheless, depletion of gonadotrophins did not result in consistent changes in cumulus respiration. The cumulus oxygen consumption was different after hypophysectomy and pentobarbitone treatment and neither treatment caused a decrease in respiration in the way that exposure to gonadotrophin does. Pentobarbitone treatment did not affect the respiration of cumulus complexes significantly, but hypophysectomy led to a marked increase in respiration in the cyclic animals by $6 \mathrm{~h}$ while having no effect on cumulus respiration in PMSGtreated immature animals. Cumulus respiration did not increase when isolated follicles from cyclic rats were cultured in a gonadotrophin-free medium. Hence, it does not seem that depletion of gonadotrophins per se leads to an increase in cumulus respiration. Morphological as well as bio- 
chemical changes associated with atresia occurring 6-24 h after hypophysectomy are similar to those observed after 2-4 days of pentobarbitone treatment (Braw \& Tsafriri, 1980; Uilenbroek et al., 1980; Braw et al., 1981). Since cumulus respiration was changed after hypophysectomy only in the cyclic animals and not at all after pentobarbitone treatment, this response cannot be attributed to the atretic process, and or be considered as a specific response associated with hypophysectomy. There are very few reports in the literature about metabolic changes immediately following hypophysectomy. The $\mathrm{CO}_{2}$ production in rat epididymal fat pads decreases within 1 day after operation (O. Isaksson \& A. Lindahl, personal communication), but to our knowledge there are no reports of an acute stimulation of metabolism in any tissue after hypophysectomy.

The present study has thus shown that the maturation-like changes in the oocyte during atresia induced by hypophysectomy or pentobarbitone treatment are accompanied by changes in oxygen consumption similar to those occurring during normal maturation, whereas there are no consistent changes in cumulus oxygen consumption that can be directly attributed to the atresia. The mechanism behind the maturation-like changes remains to be established. It might be that the inhibition of meiosis suggested as being exerted by the follicular cells (Foote \& Thibault, 1969; Tsafriri \& Channing, 1975) is interrupted by the atretic degeneration. This would permit resumption of oocyte meiosis in a manner similar to normal maturation until the degenerative process affects the oocyte as well. That oocyte maturation during atresia is similar to normal maturation is suggested not only by the present findings on oocyte respiration, but also by the finding that maturing oocytes isolated from atretic follicles can be fertilized (sheep: Moor \& Trounson, 1977; rat: R. H. Braw, unpublished).

The present study was generously supported by the Rockefeller and Ford Foundations and the Swedish Medical Research Council (No. 6350). The stay of C.M. in Israel was made possible by a scholarship from CIBA-Geigy Ltd. The contribution of S.B. and R.H.B. constitutes part of the requirements for the Ph.D. degree of the Feinberg Graduate School. Able technical assistance was provided by Miss A.-S. Magnusson.

\section{References}

Ahrén, K., Dekel, N., Hamberger, L., Hillensjö, T., Hultborn, R., Magnusson, C. \& Tsafriri, A. (1978) Metabolic and morphological changes produced by gonadotrophins and cyclic AMP in the oocyte and cumulus oophorus of preovulatory rat follicles. Annls Biol. anim. Biochim. Biophys. 18, 409-417.

Braw, R.H. \& Tsafriri, A. (1980) Follicles explanted from pentobarbitone-treated rats provide a model for atresia. J. Reprod. Fert. 59, 259-265.

Braw, R.H. \& Tsafriri, A. (1981) Physiological correlates of experimentally induced atresia. In Development and Function of Reproductive Organs, pp. 319-324. Eds A. G. Byskov \& H. Peters. Excerpta Medica, Amsterdam.

Braw, R.H., Bar Ami, S. \& Tsafriri, A. (1981) Effect of hypophysectomy on atresia of rat preovulatory follicles. Biol. Reprod. 25, 989-996.

Byskov, A.G. (1978) Follicular atresia. In The Vertebrate Ovary, pp. 533-562. Ed. R. E. Jones. Plenum, New York.

Dekel, N., Hultborn, R., Hillensjö, T., Hamberger, L. \& Kraicer, P. (1976) Effect of luteinizing hormone on respiration of the preovulatory cumulus oophorus of the rat. Endocrinology 98, 498-504.

Ekholm, C., Hillensjö, T. \& Isaksson, O. (1981) Gonado- tropin releasing hormone agonists stimulate oocyte meiosis and ovulation in hypophysectomized rats. Endocrinology 108, 2022-2024.

Foote, W.D. \& Thibault, C. (1969) Recherches expérimentales sur la maturation in vitro des ovocytes de truie et de veau. Annls Biol. anim. Biochim. Biophys. 9, 329-349.

Hultborn, R. (1974) A spectrophotometric method for analysis of oxygen consumption in vitro on the microscale. Acta physiol. scand., Suppl. 404, 1-47.

Magnusson, C. \& Hillensjö, T. (1981) Further studies on the gonadotrophin-induced inhibition of respiration in the preovulatory rat cumulus oophorus. Acta physiol. scand. 113, 17-21.

Magnusson, C., Hillensjö, T., Tsafriri, A., Hultborn, R. \& Ahrén, K. (1977) Oxygen consumption of maturing rat oocytes. Biol. Reprod. 17, 9-15.

Moor, R.M. \& Trounson, A.O. (1977) Hormonal and follicular factors affecting maturation of sheep oocytes in vitro and their subsequent developmental capacity. J. Reprod. Fert. 49, 101-109.

Tsafriri, A. \& Channing, C.P. (1975) An inhibitory influence of granulosa cells and follicular fluid upon porcine oocyte meiosis in vitro. Endocrinology 96,922 927. 
Tsafriri, A. \& Kraicer, P.F. (1972) The time sequence of ovum maturation in the rat. J. Reprod. Fert. 29, 387393.

Tsafriri, A., Lindner, H.R., Zor, U. \& Lamprecht, S.A. (1972) In-vitro induction of meiotic division in follicle-enclosed rat oocytes by LH, cyclic AMP and prostaglandin $\mathrm{E}_{2}$. J. Reprod. Fert. 31, 39-50.

Uilenbroek, J.Th.J., Woutersen, P.J.A. \& van der Schoot, P. (1980) Atresia of preovulatory follicles: gonadotro- pin binding and steroidogenic activity. Biol. Reprod. 23, 219-229.

Woolf, C.M. (1968) Principles of Biometry, lst edn. van Nostrand, Princeton.

Zarrow, M.X., Yochim, J.M. \& McCarthy, J.L. (1964) Hypophysectomy, intraaural method. In Experimental Endocrinology. A Sourcebook of Basic Techniques, pp. 310-312. Academic Press, New York.

Received 19 August 1982 